\title{
Biochemical Profiling Study in Umbilical Cord Blood as Predictors of Neonatal Damage
}

\author{
Sebastian Gruccio ${ }^{\mathrm{a}}$, Maria Beatriz Di Carlo ${ }^{\mathrm{a}}$, Marcela Pandolfo ${ }^{\mathrm{a}}$, Gabriela Santa Cruz ${ }^{\mathrm{a}}$, \\ Maria Sol Touzon ${ }^{\mathrm{a}}$, Gustavo Negria ${ }^{\mathrm{a}}$, Rodolfo Giuliano ${ }^{\mathrm{b}}$, Hilda Ruda Vega ${ }^{\mathrm{b}}$, \\ Manuel Vazquez Blanco ${ }^{c}$, Beatriz Elizabeth Perazzi ${ }^{\mathrm{a}, \mathrm{d}}$
}

\begin{abstract}
Background: During pregnancy inflammatory, metabolic and immunologic disorders that affect differently the fetus, are known. These could be early disorders: abortion, intrauterine growth retardation, low birth weight and neonatal death; or late disorders: cardiovascular and metabolic disease in adults. The objective was to analyze different biochemical parameters in maternal venous blood and newborn's umbilical cord blood (UCB) from healthy and pathological mothers for early detection of future perinatal complications.
\end{abstract}

Methods: Maternal venous blood (283) and UCB (283) were analyzed. The patients were consecutively, prospectively and transversally studied. Delivery: cesarean section. Mothers and newborns were classified: control group $(\mathrm{C})(\mathrm{n}=99)$ and pathological group (P) $(\mathrm{n}=184)$. Glucose, urea, creatinine, uric acid (UA), bilirubin (Bi), proteins (PT), albumin (Alb), transaminases (ALT/AST), alkaline phosphatase, gamma-glutamyl transpeptidase (GGT), creatinkinasa $(\mathrm{CK})$, lactate dehydrogenase (LDH), iron, calcium, phosphorus, magnesium, sodium, potassium $(\mathrm{K})$, chlorine, cholesterol (Chol), triglycerides (TG) and hsCRP were determined by recommended methods. Student's $t$ and Mann-Whitney tests were applied, $\mathrm{P}<0.05$.

Results: P newborns from P mothers showed significant decrease: in gestation weeks $(\mathrm{GW})$ and newborn weight $(\mathrm{NW})$ with respect to $\mathrm{C}$ newborns from $\mathrm{C}$ mothers $(\mathrm{P}<0.001)$; significant increases in Chol, TG, UA, K, Bi, AST and GGT (P: 0.01, < 0.001, 0.03, $<0.001,0.04,<0.001,<0.001$, respectively) and significant de-

Manuscript accepted for publication January 28, 2014

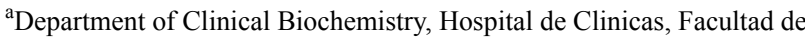
Farmacia y Bioquimica, Universidad de Buenos Aires, Buenos Aires, Argentina

bobstetrics Division, Hospital de Clinicas, Universidad de Buenos Aires, Buenos Aires, Argentina

${ }^{\mathrm{c}}$ Cardiology Division, Hospital de Clinicas, Universidad de Buenos

Aires, Buenos Aires, Argentina

${ }^{\mathrm{d}}$ Corresponding author: Beatriz Elizabeth Perazzi, Department of Clinical Biochemistry, Hospital de Clinicas, Facultad de Farmacia y Bioquimica, Universidad de Buenos Aires, Cordoba 2351 (1120) Buenos

Aires, Argentina. Email: bperazzi@ffyb.uba.ar

doi: http://dx.doi.org/10.14740/ijcp140e creases in $\mathrm{CK}$, PT and Alb $(\mathrm{P}<0.001)$. P mothers showed significant increase in UA, ALT, AST, GGT (P: 0.04, 0.02, 0.04, < 0.001, respectively) with respect to $\mathrm{C}$ mothers.

Conclusions: The decrease in GW and NW in P newborns with respect to $\mathrm{C}$ would be related to intrauterine growth restriction (IUGR) accompanying these disorders; increases in Chol, TG, UA, $\mathrm{K}, \mathrm{Bi}, \mathrm{AST}$ and GGT would be related to cellular destruction associated to maternal disorders and deficit in pulmonary development by IUGR respectively, whereas decreases in CK, PT and Alb to IUGR. Increase in UA, ALT, AST and GGT from P mothers with respect to $\mathrm{C}$ would be associated to inflammatory process with liver alterations. A future study including greater number of samples and analysis of each maternal disorder is proposed to obtain early markers of neonatal damage and to prevent future perinatal complications.

Keywords: Biochemical profiling study; Predictors; Umbilical cord blood; Neonatal damage

\section{Introduction}

Various complex disorders which can impact on the fetus at variable degrees are known to affect pregnant women. In some cases, the etiology of these disorders is already well known whereas in some other cases it is still under study. Poor or inadequate nutrition, smoking, alcohol abuse, lower genital tract infections, anemia, hypertension, gestational or non-gestational diabetes, obesity, metabolic and antiphospholipid syndromes, among others, are some of the maternal conditions that may have an effect on fetal growth [1-8]. These maternal disorders affect the environment where the fetus is developing and may produce metabolic, immune, vascular, hemodynamic and renal alterations [9-12]. These alterations can have early manifestations, either during intrauterine life or at birth, such as abortion, intrauterine growth restriction (IUGR), low birth weight, neonatal mortality; or they may occur later causing a greater impact on adult life. As a result, different diseases such as poor glucose homeostasis, insulin resistance, type 2 diabetes [13-15], the metabolic syndrome, obesity, hypertension [16-18], osteoporosis 
[19-20], cardiovascular disease, endothelial dysfunction and coronary heart disease may be a consequence of these alterations [1, 21-23]. On the other hand, slow fetal growth in utero may be associated with an increase in the accumulation of nutrients to the adipose tissue during fetal development which could later result in accelerated weight gain during childhood [24, 25], and possibly, in a greater risk of coronary heart disease, hypertension and type 2 diabetes. Furthermore, there is a continuous relation between birth weight and future risk [26]. Moreover, prematurity itself, regardless of the size for gestational age, has been associated with insulin resistance and glucose intolerance in prepuberal children [27], which could later impact on young adults and may be accompanied by elevated blood pressure [28]. Therefore, what happens during the fetal development in utero seems to condition some diseases occurring in adult life through different mechanisms.

On the other hand, all these maternal conditions are mostly related to inflammatory processes [29-31]. During these processes, a series of characteristic events are triggered, starting with the participation of polymorphonuclear neutrophils (PMN) and ending with damage to the affected tissue $[32,33]$. This inflammation has consequences at molecular, cellular, tissular and systemic levels. Consequently, inflammation has not only been associated with infectious processes but also with hypertension [34], preeclampsia [35], diabetes and the metabolic syndrome [36].

However, there is scant information in the literature with respect to C-reactive protein (CRP) and proinflammatory interleukin levels as well as practically no reference to the levels of metabolites and enzymes in newborns' umbilical cord blood (UCB) from mothers with these conditions.

The objective of this work was to analyze different biochemical parameters (BPs) in maternal venous blood and healthy newborns' UCB from healthy mothers, as well as in newborns' UCB from mothers with underlying conditions and diseases associated with gestation, with the aim of evaluating the possible role of some of them as early predictive markers of perinatal damage such as reduced fetal growth (low weight, IUGR, fetal distress and/or premature birth), in order to prevent future maternal and perinatological complications.

\section{Material and Methods}

\section{Patients}

Two hundred and eighty-three (283) venous blood samples from mothers admitted for delivery at the Obstetrics Division in the Hospital de Clinicas of the University of Buenos Aires and 283 samples from the UCB of their respective newborns were collected from January 2010 to January 2012. The patients were consecutive, prospective and transversally stud- ied, and all the mothers and their respective neonates were included in this study.

In all cases, delivery was via cesarean section. The mothers and their newborns were classified into two groups: the control group $(n=99)$, healthy mothers without underlying or gestational disorders; and the pathological group $(\mathrm{n}=$ 184). The underlying maternal diseases included: diabetes, hypertension, antiphospholipid syndrome, hyper/hypotiroidism, intrahepatic cholestasis and genital infections, whereas the disorders in the newborns were: IUGR and/or fetal distress.

This study was approved by the Hospital Ethics Committee. All women in the study gave their informed consent to participate.

\section{Methods and statistical analysis}

Twenty-three biochemical markers were studied as numerical continuous variables. These were measured by internationally recommended methods, in COBAS Auto-analyzer 6000, C-501 Module-Roche Diagnostics, Germany: glucose (Glu) (hexokinase-enzymatic method), urea (U) (UV-kinetic method), creatinine $(\mathrm{Cr})$ (rate blanked and compensated Jaffe-Kinetic method), uric acid (UA) (enzimatic-colorimetric method), total bilirubin (TB) (colorimetric method), total proteins (TP) (Biuret-colorimetric method), albumin (Alb) (colorimetric bromocresol green method), alanine aminotransferase (ALT) (IFCC- kinetic method), aspartate aminotransferase (AST) (IFCC-kinetic method), alkaline phosphatase (ALP) (DGKC kinetic method), gamma-glutamyl transpeptidase (GGT) (IFCC-kinetic method), creatine kinase (CK) (IFCC-kinetic method), lactate dehydrogenase (LDH) (DGKC-kinetic method), ferremia (Fe) (colorimetric method), calcium ( $\mathrm{Ca}$ ) (colorimetric-endpoint method), phosphorus (P) (colorimetric-endpoint method), magnesium $(\mathrm{Mg})$ (colorimetric-endpoint method), sodio $(\mathrm{Na})$ (potentiometric method-selective ion), potassium (K) (potentiometric method-selective ion), chlorine $(\mathrm{Cl})$ (potentiometric method-selective ion), cholesterol (Cho) (CHOD/PAP-enzymatic method), triglycerides (TG) (GPO/Px-enzymatic method) and high sensitivity $\mathrm{C}$ reactive protein (hsCRP) (immunoturbidimetric method).

The statistical analysis of the comparison of gestational weeks, neonatal weight and BPs of both groups was performed by using a parametric test (Student's t) and a nonparametric test (Mann-Whitney), for independent samples. Two tailed tests were used throughout. A P value $<0.05$ was considered statistically significant. InfoStat v.2011 (National University of Cordoba, Argentina) software was used.

\section{Results}

Maternal age and gestational weeks, neonatal weight and 
Table 1. Maternal Age and Gestation Weeks, Newborn Weight and Biochemical Parameters in Maternal Venous Blood and Umbilical Cord Blood in Control and Pathological Groups Expressed as the Mean and Their Respective Standard Deviation Values

Maternal venous blood

Controls

(99)

$\begin{array}{lll}27 \pm 7 & 28 \pm 8 & \text { ns } \\ 38.8 \pm 1.5 & 37.1 \pm 2.8 & <0.001^{*}\end{array}$

Mothers age (years)

Gestation weeks

Newborn weight (g)

Glucose (mg/dL)

Urea $(\mathrm{mg} / \mathrm{dL})$

Cholesterol (mg/dL)

Triglycerides (mg/dL)

Uric acid (mg/dL)

Creatinine (mg/dL)

Calcium (mg/dL)

Phosphorus (mg/dL)

Magnesium (mg/dL)

Sodium $(\mathrm{mEq} / \mathrm{L})$

Potassium (mEq/L)

Chlorine $(\mathrm{mEq} / \mathrm{L})$

Iron $(\mu \mathrm{g} / \mathrm{dL})$

Total bilirubin (mg/dL)

ALT (IU/L)

AST (IU/L)

ALP (IU/L)

LDH (IU/L)

CK (IU/L)

GGT (IU/L)

hsCRP (mg(L)

Albumin (g/dL)

Protein (g/dL)

$\begin{array}{lll}77 \pm 29 & 81 \pm 52 & \\ 22 \pm 7 & 22 \pm 9 & n \\ 236 \pm 54 & 230 \pm 58 & n \\ 208 \pm 71 & 218 \pm 102\end{array}$

$4.5 \pm 1.2$

$0.6 \pm 0.1$

$8.7 \pm 0.6$

$8.7 \pm 0.7$

$4.1 \pm 1.2$

$4.2 \pm 1.3$

$1.8 \pm 0.2$

$1.8 \pm 0.2$

$138 \pm 13$

$140 \pm 5$

$4.3 \pm 0.6$

$4.4 \pm 1.4$

$106 \pm 5$

$106 \pm 5$

$66 \pm 47$

$65 \pm 49$

$0.3 \pm 0.2$

$0.3 \pm 0.2$

$11 \pm 8$

$18 \pm 41$

$24 \pm 8$

$29 \pm 35$

$304 \pm 160$

$315 \pm 190$

$443 \pm 133$

$452 \pm 136$

$229 \pm 174$

$198 \pm 203$

$12 \pm 7$

$20 \pm 26$

$53 \pm 67$

$59 \pm 68$

$3.2 \pm 0.5$

$3.1 \pm 0.3$

$5.8 \pm 0.7$

$5.8 \pm 0.6$

\section{Umbilical cord blood}

\begin{tabular}{|c|c|c|c|}
\hline & $3,394 \pm 371$ & $2,936 \pm 784$ & $<0.001^{*}$ \\
\hline ns & $58 \pm 29$ & $55 \pm 31$ & ns \\
\hline ns & $20 \pm 5$ & $20 \pm 6$ & ns \\
\hline ns & $68 \pm 27$ & $74 \pm 33$ & $0.01 *$ \\
\hline ns & $32 \pm 13$ & $37 \pm 48$ & $<0.001 *$ \\
\hline $0.04^{*}$ & $4.4 \pm 1.2$ & $4.7 \pm 1.4$ & $0.03 *$ \\
\hline ns & $0.5 \pm 0.2$ & $0.5 \pm 0.2$ & ns \\
\hline ns & $10.0 \pm 1.3$ & $10.1 \pm 1.0$ & ns \\
\hline ns & $6.1 \pm 2.1$ & $6.3 \pm 2.2$ & ns \\
\hline ns & $1.9 \pm 0.3$ & $2.0 \pm 0.4$ & ns \\
\hline ns & $138 \pm 8$ & $139 \pm 8$ & ns \\
\hline ns & $5.7 \pm 1.3$ & $6.3 \pm 1.8$ & $<0.001 *$ \\
\hline ns & $105 \pm 7$ & $106 \pm 7$ & ns \\
\hline ns & $151 \pm 38$ & $146 \pm 49$ & ns \\
\hline ns & $1.5 \pm 0.9$ & $1.7 \pm 1.3$ & $0.04 *$ \\
\hline $0.02 *$ & $8 \pm 4$ & $8 \pm 6$ & ns \\
\hline $0.04 *$ & $35 \pm 11$ & $38 \pm 20$ & $<0.001 *$ \\
\hline ns & $337 \pm 208$ & $328 \pm 181$ & ns \\
\hline ns & $804 \pm 353$ & $848 \pm 336$ & ns \\
\hline ns & $312 \pm 190$ & $275 \pm 121$ & $<0.001^{*}$ \\
\hline$<0.001 *$ & $96 \pm 56$ & $118 \pm 77$ & $<0.001 *$ \\
\hline ns & $0.4 \pm 0.8$ & $0.2 \pm 0.3$ & ns \\
\hline ns & $3.8 \pm 0.3$ & $3.6 \pm 0.5$ & $<0.001^{*}$ \\
\hline ns & $5.6 \pm 0.6$ & $5.3 \pm 0.8$ & $<0.001 *$ \\
\hline
\end{tabular}

Pathological

(184)

$\begin{array}{ll}\text { Controls } & \text { Pathological } \\ \text { (99) } & (184)\end{array}$

$\mathbf{P}$

ALP: alkaline phosphatase; GGT: gamma-glutamyl transpeptidase; CK: creatine kinase; LDH: lactate dehydrogenase; hsCRP: high sensitivity C-reactive protein. *Statistically significant difference; ns: non-significant difference. 
all BPs of maternal venous blood and UCB from both the pathological and control groups were expressed as the mean and the respective standard deviation values (Table 1).

Pathological neonates $(n=184)$ from pathological mothers $(n=184)$ showed a significant decrease in maternal gestation weeks and in newborn weight with respect to control newborns $(n=99)$ from control mothers $(n=99)(P$ $<0.001$ ), as well as significant increases in Cho, TG, UA, K, TB, AST and GGT values in UCB (P: 0.01, < 0.001, 0.03, $<0.001,0.04,<0.001$ and $<0.001$, respectively) and significant decreases in $\mathrm{CK}$, TP and Alb values $(\mathrm{P}<0.001)$. The other biochemical markers did not show significant differences in UCB of pathological newborns with respect to those in the control group (Table 1).

A significant increase in UA, ALT, AST and GGT values was observed in venous blood of pathological mothers with respect to those in control mothers (P: 0.04, 0.02, 0.04 and $<$ 0.001 , respectively). There were no significant differences in the other biochemical markers (Table 1).

\section{Discussion}

The decrease observed in gestation weeks and newborn weight in pathological newborns from pathological mothers with respect to the control group might be associated with the IUGR related to these disorders.

The observed increase in Cho, TG, UA, K, TB and AST values in UCB in pathological newborns from pathological mothers with respect to those in the control group might be related to cellular destruction associated with the maternal condition, whereas the increase in GGT levels in UCB of these newborns might be due to a deficit in pulmonary development as a result of IUGR. There are few studies in the bibliographical references referring to the normal levels and their alterations, in terms of metabolites and enzymes, in newborns' UCB from mothers with underlying metabolic disorders, infections of the lower genital tract, underlying inflammatory or immunological conditions and diseases associated with gestation and informing about the way these alterations impact on the newborn.

Similarly to what was observed in this study, the increase in the levels of certain metabolites such as cholesterol and triglycerides in maternal blood of patients with preeclampsia has been described as a result of the cellular damage it produces, suggesting a possible role in the pathophysiology of the syndrome [37]. Thus, likewise, the different maternal disorders included in this study, which have in common the presence of cellular damage and inflammation, such as diabetes, hypertension, the antiphospholipid syndrome and genital infections, among others, might impact on the newborn by producing an increase in intracellular ions such as $\mathrm{K}$ and intracellular enzymes such as AST and other metabolites such as UA and TB.
Furthermore, the decrease observed in $\mathrm{CK}$, total protein and albumin levels in pathological newborn's UCB with respect to control newborns would be due to IUGR.

Furthermore, the decrease of specific metabolites such as glucose in blood obtained by cordcentesis in fetuses with IUGR has been described, considering that glucose is the main substrate for fetal energy metabolism and its demand increases as growth progresses [38]. This fact could be the result of alterations in the placenta or in fetal glucose metabolism [39, 40]. Moreover, there have been reports of high concentrations of triglycerides and low levels of free fatty acids in fetuses with IUGR, similarly to what was observed in the present study [38]. These alterations are the result of chronic hypoglycemia with compensatory lipolysis and an inability to hydrolize circulating triglycerides allowing a decrease in their use as fat deposits. The decrease in free fatty acids impacts on the fetus since they are major components of the cell membrane and a source of energy for fetal development and growth [41]. In addition, it has been reported that in fetuses with cardiac defects and IUGR, the levels of troponine $\mathrm{T}$ in umbilical venous blood are increased by $12 \%$ and $20 \%$, respectively [42]. Nevertheless, unlike what has been observed in our study, other authors have reported that AST values in UCB from newborns affected by IUGR were not different from those observed in normal newborns; even lower ALT values have been described in newborns with IUGR with respect to normal newborns, which suggests that the reduced activity may be due to hepatic immaturity of the newborn to produce enzymes [43].

On the other hand, an increase in AU, ALT, AST and GGT levels was observed in venous blood of the pathological mothers with respect to those in the controls, which were probably associated with the inflammatory process related to the studied maternal diseases and hepatic alterations. In this respect, it has been linked to inflammation in the pathogenesis of hypertension [34] and particularly, in preeclampsia [44]. Furthermore, its impact on the development of longterm cardiovascular disease is being evaluated [45]. Recent publications have also considered chronic subclinical inflammation as a pathophysiological factor causing type 2 diabetes, gestational diabetes, the metabolic syndrome, obesity, atherosclerotic cardiovascular disease and myocardial infarction [46]. Even though no significant increases in hsCRP values were observed in maternal blood, this parameter would be a predictor of the development of these disorders [47-50]. However, there are few studies referring to hsCRP levels in UCB as early markers of fetal distress risk associated with severe maternal disorders such as diabetes and the antiphospholipid syndrome and with typical conditions related to gestation such as preeclampsia, spontaneous abortion and premature rupture of fetal membranes. In our study, no differences in hsCRP levels were observed in UCB of pathological newborns with respect to the control group. Although most of the maternal diseases included in this 
study are related to inflammatory processes, such processes were not reflected in hsCRP levels in pathological newborns' UCB. This lack of correlation, also described by other authors, suggests that hsCRP levels in amniotic fluid have fetal origin [51].

\section{Conclusions}

In view of the differences observed in UCB from pathological newborns with respect to those in the control group, a future study including a greater number of samples is proposed with the aim of studying each specific maternal disease and obtaining early markers of neonatal damage that could prevent future maternal and perinatological complications.

\section{Acknowledgement}

We are very grateful to all the pregnant women who participated in this survey and to the medical residents and nursing staff that helped in the collection of maternal blood and newborns' umbilical cord blood samples.

\section{Financial Support}

This work was supported by Universidad de Buenos Aires grant UBACYT 01/K24 project from the Facultad de Farmacia y Bioquimica.

\section{Conflict of Interest}

We do no have any conflict of interests.

\section{Ethical Approval}

This study was approved by the Hospital Ethics Committee. All women in the study gave their informed consent to participate.

\section{References}

1. Fernandez-Twinn DS, Ozanne SE. Mechanisms by which poor early growth programs type-2 diabetes, obesity and the metabolic syndrome. Physiol Behav. 2006;88(3):234-243.

2. Bernstein IM, Mongeon JA, Badger GJ, Solomon L, Heil SH, Higgins ST. Maternal smoking and its association with birth weight. Obstet Gynecol. 2005;106(5 Pt 1):986-991.

3. Ohmi H, Hirooka K, Mochizuki Y. Fetal growth and the timing of exposure to maternal smoking. Pediatr Int. 2002;44(1):55-59.

4. Levy A, Fraser D, Katz M, Mazor M, Sheiner E. Maternal anemia during pregnancy is an independent risk factor for low birthweight and preterm delivery. Eur J Obstet Gynecol Reprod Biol. 2005;122(2):182-186.

5. Scanlon KS, Yip R, Schieve LA, Cogswell ME. High and low hemoglobin levels during pregnancy: differential risks for preterm birth and small for gestational age. Obstet Gynecol. 2000;96(5 Pt 1):741-748.

6. Kramer MS. Determinants of low birth weight: methodological assessment and meta-analysis. Bull World Health Organ. 1987;65(5):663-737.

7. Lund R, Modvig J, Hilden J, Rosdahl N, Kure L, Schmidt K. Risk of low birthweight in social districts of Copenhagen. Scand J Public Health. 1999;27(2):89-93.

8. Clausson B, Cnattingius S, Axelsson O. Preterm and term births of small for gestational age infants: a population-based study of risk factors among nulliparous women. Br J Obstet Gynaecol. 1998;105(9):1011-1017.

9. Ross MG, Beall MH. Adult sequelae of intrauterine growth restriction. Semin Perinatol. 2008;32(3):213218.

10. Smith NH, Ozanne SE. Intrauterine origins of metabolic disease. Reviews in Gynecol Perinatal Practice. 2006;6(3-4):211-217.

11. Jones RH, Ozanne SE. Fetal programming of glucoseinsulin metabolism. Mol Cell Endocrinol. 2009;297(12):4-9.

12. Simmons R. Perinatal programming of obesity. Semin Perinatol. 2008;32(5):371-374.

13. Lithell HO, McKeigue PM, Berglund L, Mohsen R, Lithell UB, Leon DA. Relation of size at birth to noninsulin dependent diabetes and insulin concentrations in men aged 50-60 years. BMJ. 1996;312(7028):406-410.

14. Forsen T, Eriksson J, Tuomilehto J, Reunanen A, Osmond C, Barker D. The fetal and childhood growth of persons who develop type 2 diabetes. Ann Intern Med. 2000;133(3):176-182.

15. Newsome CA, Shiell AW, Fall CH, Phillips DI, Shier $\mathrm{R}$, Law CM. Is birth weight related to later glucose and insulin metabolism?--A systematic review. Diabet Med. 2003;20(5):339-348.

16. Curhan GC, Chertow GM, Willett WC, Spiegelman D, Colditz GA, Manson JE, Speizer FE, et al. Birth weight and adult hypertension and obesity in women. Circulation. 1996;94(6):1310-1315.

17. Huxley RR, Shiell AW, Law CM. The role of size at birth and postnatal catch-up growth in determining systolic blood pressure: a systematic review of the literature. J Hypertens. 2000;18(7):815-831.

18. Yliharsila H, Eriksson JG, Forsen T, Kajantie E, Osmond C, Barker DJ. Self-perpetuating effects of birth size on blood pressure levels in elderly people. Hypertension. 
2003;41(3):446-450.

19. Cooper C, Eriksson JG, Forsen T, Osmond C, Tuomilehto J, Barker DJ. Maternal height, childhood growth and risk of hip fracture in later life: a longitudinal study. Osteoporos Int. 2001;12(8):623-629.

20. Dennison EM, Syddall HE, Sayer AA, Gilbody HJ, Cooper C. Birth weight and weight at 1 year are independent determinants of bone mass in the seventh decade: the Hertfordshire cohort study. Pediatr Res. 2005;57(4):582586.

21. Rich-Edwards JW, Stampfer MJ, Manson JE, Rosner B, Hankinson SE, Colditz GA, Willett WC, et al. Birth weight and risk of cardiovascular disease in a cohort of women followed up since 1976. BMJ. 1997;315(7105):396-400.

22. Leon DA, Lithell HO, Vagero D, Koupilova I, Mohsen R, Berglund L, Lithell UB, et al. Reduced fetal growth rate and increased risk of death from ischaemic heart disease: cohort study of 15000 Swedish men and women born 1915-29. BMJ. 1998;317(7153):241-245.

23. Gluckman PD, Hanson MA, Cooper C, Thornburg KL. Effect of in utero and early-life conditions on adult health and disease. N Engl J Med. 2008;359(1):61-73.

24. Bhargava SK, Sachdev HS, Fall CH, Osmond C, Lakshmy R, Barker DJ, Biswas SK, et al. Relation of serial changes in childhood body-mass index to impaired glucose tolerance in young adulthood. N Engl J Med. 2004;350(9):865-875.

25. Barker DJ, Osmond C, Forsen TJ, Kajantie E, Eriksson JG. Trajectories of growth among children who have coronary events as adults. N Engl J Med. 2005;353(17):1802-1809.

26. Barker DJ. In utero programming of chronic disease. Clin Sci (Lond). 1998;95(2):115-128.

27. Hofman PL, Regan F, Jackson WE, Jefferies C, Knight DB, Robinson EM, Cutfield WS. Premature birth and later insulin resistance. N Engl J Med. 2004;351(21):21792186.

28. Hovi P, Andersson S, Eriksson JG, Jarvenpaa AL, Strang-Karlsson S, Makitie O, Kajantie E. Glucose regulation in young adults with very low birth weight. N Engl J Med. 2007;356(20):2053-2063.

29. Ali H, Haribabu B, Richardson RM, Snyderman R. Mechanisms of inflammation and leukocyte activation. Med Clin North Am. 1997;81(1):1-28.

30. Luster AD. Chemokines--chemotactic cytokines that mediate inflammation. N Engl J Med. 1998;338(7):436445.

31. Gabay C, Kushner I. Acute-phase proteins and other systemic responses to inflammation. $\mathrm{N}$ Engl J Med. 1999;340(6):448-454.

32. Mosca L. C-reactive protein--to screen or not to screen? N Engl J Med. 2002;347(20):1615-1617.

33. Witko-Sarsat V, Rieu P, Descamps-Latscha B, Lesavre
P, Halbwachs-Mecarelli L. Neutrophils: molecules, functions and pathophysiological aspects. Lab Invest. 2000;80(5):617-653.

34. Sesso HD, Buring JE, Rifai N, Blake GJ, Gaziano JM, Ridker PM. C-reactive protein and the risk of developing hypertension. JAMA. 2003;290(22):2945-2951.

35. Redman CW, Sacks GP, Sargent IL. Preeclampsia: an excessive maternal inflammatory response to pregnancy. Am J Obstet Gynecol. 1999;180(2 Pt 1):499-506.

36. Pickup JC, Mattock MB, Chusney GD, Burt D. NIDDM as a disease of the innate immune system: association of acute-phase reactants and interleukin- 6 with metabolic syndrome X. Diabetologia. 1997;40(11):1286-1292.

37. Chappell LC, Seed PT, Briley A, Kelly FJ, Hunt BJ, Charnock-Jones DS, Mallet AI, et al. A longitudinal study of biochemical variables in women at risk of preeclampsia. Am J Obstet Gynecol. 2002;187(1):127-136.

38. Molina LM, Hernandez Barbosa R. Retardo del crecimiento intrauterino (RCIU) y sus alteraciones bioquimicas. NOVA. 2005;3(3):88-94.

39. Karsdorp VH, van Vugt JM, Jakobs C, Dekker GA, van Geijn HP. Amino acids, glucose and lactate concentrations in umbilical cord blood in relation to umbilical artery flow patterns. Eur J Obstet Gynecol Reprod Biol. 1994;57(2):117-122.

40. Nicolini U, Nicolaidis P, Fisk NM, Vaughan JI, Fusi L, Gleeson R, Rodeck CH. Limited role of fetal blood sampling in prediction of outcome in intrauterine growth retardation. Lancet. 1990;336(8718):768-772.

41. Oey NA, den Boer ME, Wijburg FA, Vekemans M, Auge J, Steiner C, Wanders RJ, et al. Long-chain fatty acid oxidation during early human development. Pediatr Res. 2005;57(6):755-759.

42. Kocylowski RD, Dubiel M, Gudmundsson S, Sieg I, Fritzer E, Alkasi O, Breborowicz GH, et al. Biochemical tissue-specific injury markers of the heart and brain in postpartum cord blood. Am J Obstet Gynecol. 2009;200(3):273 e271-273 e225.

43. Kocylowski R, Dubiel M, Gudmundsson S, Fritzer E, Kiserud T, von Kaisenberg C. Hepatic aminotransferases of normal and IUGR fetuses in cord blood at birth. Early Hum Dev. 2012;88(7):461-465.

44. Lopez-Jaramillo P, Herrera JA, Arenas-Mantilla M, Jauregui IE, Mendoza MA. Subclinical infection as a cause of inflammation in preeclampsia. Am J Ther. 2008;15(4):373-376.

45. Barden A. Pre-eclampsia: contribution of maternal constitutional factors and the consequences for cardiovascular health. Clin Exp Pharmacol Physiol. 2006;33(9):826830.

46. Festa A, D'Agostino R, Jr., Howard G, Mykkanen L, Tracy RP, Haffner SM. Chronic subclinical inflammation as part of the insulin resistance syndrome: the Insulin Resistance Atherosclerosis Study (IRAS). Circula- 
tion. 2000;102(1):42-47.

47. Yudkin JS, Stehouwer CD, Emeis JJ, Coppack SW. Creactive protein in healthy subjects: associations with obesity, insulin resistance, and endothelial dysfunction: a potential role for cytokines originating from adipose tissue? Arterioscler Thromb Vasc Biol. 1999;19(4):972978.

48. Retnakaran R, Hanley AJ, Raif N, Connelly PW, Sermer $\mathrm{M}$, Zinman B. C-reactive protein and gestational diabetes: the central role of maternal obesity. J Clin Endocrinol Metab. 2003;88(8):3507-3512.

49. Ridker PM, Hennekens CH, Buring JE, Rifai N. C-re- active protein and other markers of inflammation in the prediction of cardiovascular disease in women. $\mathrm{N}$ Engl J Med. 2000;342(12):836-843.

50. Kinjo K, Sato H, Ohnishi Y, Hishida E, Nakatani D, Mizuno H, Imai K, et al. Impact of high-sensitivity C-reactive protein on predicting long-term mortality of acute myocardial infarction. Am J Cardiol. 2003;91(8):931935.

51. Malek A, Bersinger NA, Di Santo S, Mueller MD, Sager R, Schneider H, Ghezzi F, et al. C-reactive protein production in term human placental tissue. Placenta. 2006;27(6-7):619-625. 